\title{
An unusual outcome of papillary renal cell carcinoma with lung metastases: a case report and review of literature
}

\author{
Emmanuel Owusu Ofori ${ }^{*}$ (D), Baba Alhaji Bin Alhassan', Edwina Ayaaba Ayabilah', \\ Patrick Opoku Manu Maison², Alvin Asante-Asamani ${ }^{1}$, Henry Atawura², Ganiyu Adebisi Rahman², \\ Patrick Kafui Akakpo ${ }^{3}$, Emmanuel Gustav Imbeah ${ }^{3}$ and Prince Wilson Ofori ${ }^{4}$
}

\begin{abstract}
Background: Renal cell carcinoma (RCC) is a heterogeneous group of malignant epithelial tumors of the kidney. It accounts for more than $90 \%$ of all kidney cancers. However, papillary RCC is the second most common histologic subtype representing 10-15\% of all RCCs. The mean age of presentation for papillary RCC ranges between 59 and 63 years but more importantly when RCC is diagnosed at a younger age, the possibility of an underlying hereditary kidney cancer syndrome should be considered. RCC potentially metastasizes to many different organs with lung being the commonest site accounting for $45.2 \%$. The treatment for metastatic RCC is mostly multimodal for most patients. However, patients with untreated pulmonary metastases have been observed to have very poor prognosis with a 5-year overall survival rate of only $5 \%$ or even less and thus the need to report on the unusual outcome of our patient who had a metastatic disease.

Case presentation: The present study reports a papillary renal cell carcinoma with multiple lung metastases in a 31-year-old woman who presented with progressive right flank mass and pain with no chest symptoms. She underwent cytoreductive radical nephrectomy via a right subcostal incision. Patient, however, did not undergo metastasectomy nor palliative systemic therapy and was seen 5 years post-nephrectomy.

Conclusion: Our patient with metastatic RCC, without undergoing metastasectomy nor palliative systemic therapy, remained stable with 5-year progression-free survival post-cytoreductive nephrectomy.
\end{abstract}

Keywords: Renal cell carcinoma, Papillary RCC, Lung metastasis, Tumor, Nephrectomy

\section{Background}

Renal cell carcinoma (RCC) is a heterogeneous group of malignant epithelial tumors of the kidney. It accounts for more than $90 \%$ of all kidney cancers $[1,2]$. The most common histology subtype of RCC is clear cell followed by papillary, chromophobe and other rare histologic subtypes. The modifiable risk factors associated with RCC include obesity, cigarette smoking and hypertension [1].

\footnotetext{
*Correspondence: emma2ofori@yahoo.co.uk

${ }^{1}$ Department of Surgery, Cape Coast Teaching Hospital, Cape Coast, Ghana

Full list of author information is available at the end of the article
}

It is estimated that about $30 \%$ of patients have metastatic disease at the time of diagnosis or become apparent years after nephrectomy for clinically localized disease in nearly $40 \%$ of cases [3]. The most common site of metastasis is the lung (45.2\%), followed by bone (29.5\%), lymph nodes $(21.8 \%)$ and liver (20.3\%) [4]. The treatment for metastatic RCC (mRCC) is mostly multimodal for most patients [5]. Surgery remains the mainstream treatment for RCC localized to the kidney because the resection of primary tumors tends to be curative and provides the most effective oncological outcome [6-8]. However a metastatic tumor is practically incurable [3] and associated with short survival owing to an aggressive disease 
phenotype and lack of curative systemic treatments [912]. Cytoreductive nephrectomy and metastasectomy have both been demonstrated to have survival benefit and are relevant in the management of patients with metastatic RCC [5]. However, patients with untreated pulmonary metastases have been observed to have very poor prognosis with a 5 -year overall survival rate of only $5 \%$ or even less [13].

The urology unit of a Teaching Hospital Surgery Department has diagnosed four renal cell carcinoma over a period of 5 years (between 2014 and 2019) among 15 patients who underwent nephrectomy on account of renal tumor diagnosed on contrast-enhanced computerized tomography (CT) scans. Out of the four cases, three were papillary RCC and one RCC with rhabdoid features. However, we present this unique case report with lung metastases from papillary renal cell carcinoma that underwent cytoreductive nephrectomy and was lost to follow-up. She has had a stable and disease progressionfree 5-year survival without incidentally undergoing any palliative therapy post-surgery thus worth reporting as well as a review of literature.

\section{Case presentation}

A 31-year-old Ghanaian female was first seen at the hospital on January 27, 2015, with complaints of feeling right flank mass and right flank pain of a year duration. She had no associated hematuria, dysuria, frequency of micturition, fever, cough nor weight loss. She was not hypertensive nor diabetic and did not drink alcohol or smoke cigarette. She had no personal nor family history of ovarian cancer, uterine cancer, renal cancer and bladder cancer. On physical examination, her BMI was $27.5 \mathrm{~kg} / \mathrm{m}^{2}$ and she was not pale, afebrile, anicteric and no lymphadenopathy. Her chest air entry was adequate bilaterally in all lung fields, and breath sounds were vesicular with no added sounds. However, there was dull percussion note on right lower lung zone. Her oxygen saturation in room air was $99 \%$, blood pressure was $130 / 80 \mathrm{mmHg}$ and pulse was $82 \mathrm{bpm}$, regular and of good volume. She had a midline incisional scar from a previous left salpingectomy on account of ectopic pregnancy, and her abdomen was soft with a huge palpable right kidney mass extending from the right hypochondrium to right flank, nontender, illdefined and measuring about $12 \mathrm{~cm} \times 16 \mathrm{~cm}$ in size.

A contrast-enhanced chest and abdominal CT scan done showed a large heterogeneous mass with cystic areas likely necrosis measuring $14.5 \mathrm{~cm} \times 11.5 \mathrm{~cm} \times 11.0 \mathrm{~cm}$ in size in the anterior segment of the right kidney and spanning the entire length of the kidney (Fig. 1). A discrete minimally enhancing soft tissue mass measuring $2.6 \mathrm{~cm} \times 2.1 \mathrm{~cm}$ in the para-aortic region was seen likely metastatic lymph node. The right renal vein and inferior vena cava were grossly normal. Left kidney, liver, pancreas, gall bladder, spleen, bowel and urinary bladder were also normal. There was no evidence of ascites.

There were multiple well-defined enhancing lesions in both lung fields (about seven on each side) and left hilum consistent with metastases (Fig. 2). The mass was therefore consistent with renal cell carcinoma on the CT scan with abdominal lymphadenopathy and lung metastases.

Electrocardiogram (ECG), echocardiogram, liver function test (LFT), renal function test (RFT) and urine examination done were all normal. Patient's Eastern

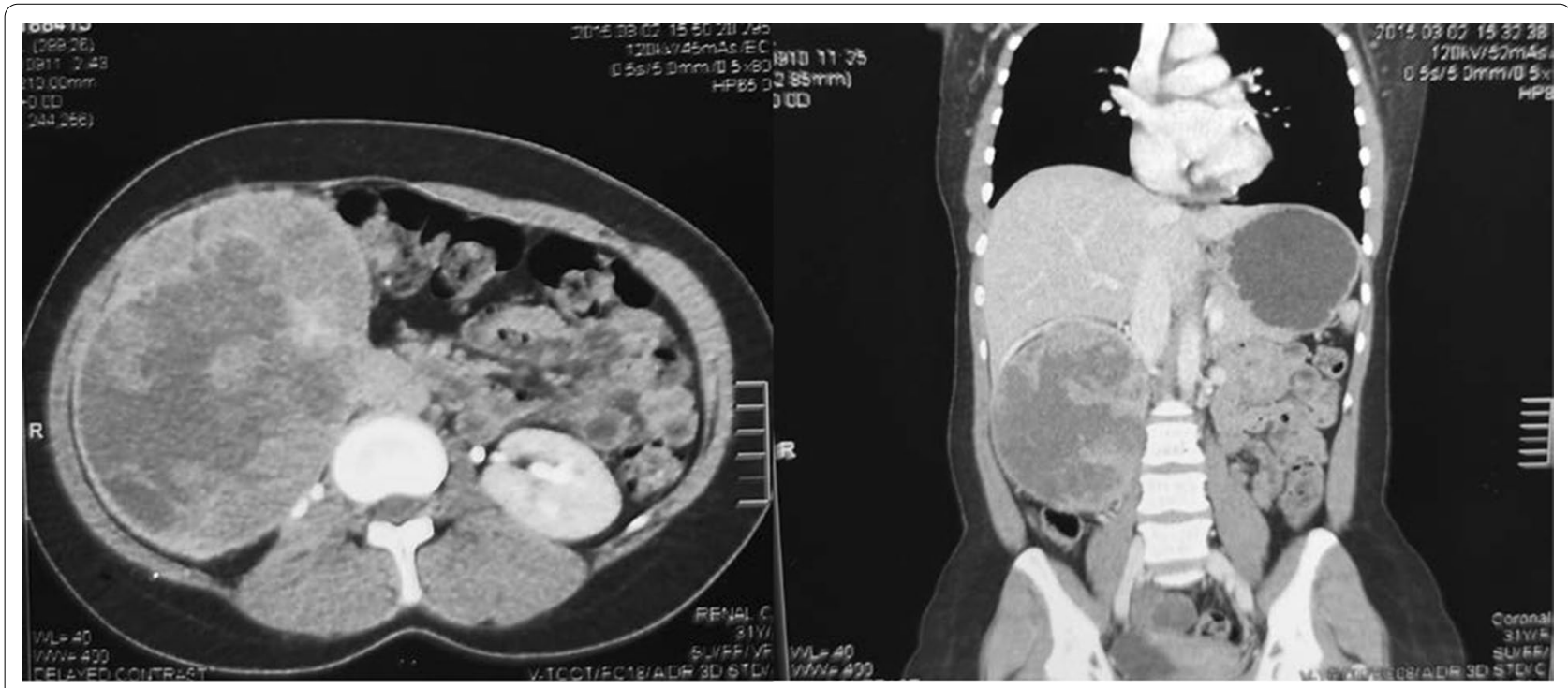

Fig. 1 Contrast-enhancing CT images of the abdomen showing a huge, well delineate, heterogeneously enhancing mass of the right kidney 


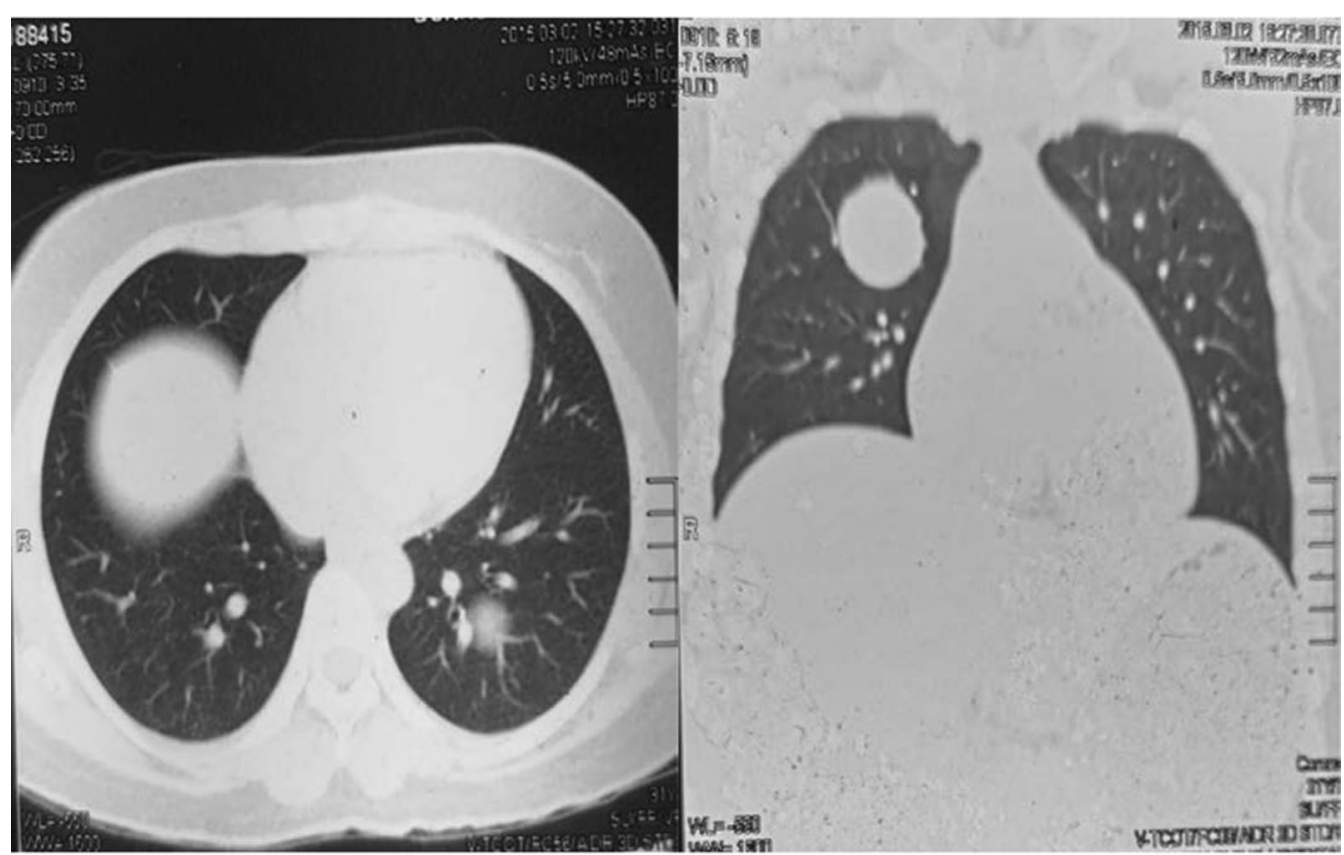

Fig. 2 Preoperative contrast-enhancing CT images of the chest showing multiple well-defined enhancing lesions in both lung fields

Cooperative Oncology Group (ECOG) performance status score was 0 at presentation.

After a multidisciplinary team (included urologists, medical oncologists, pathologists, radiologists and oncology nurses) discussion on the case, patient was planned for a cytoreductive nephrectomy and subsequently to be followed up with palliative systemic treatment. She successfully underwent right radical nephrectomy 5 weeks later using a right subcostal incision. She was discharged on postoperative day 8 with no complications.

A right kidney measuring $15 \mathrm{~cm} \times 10 \mathrm{~cm} \times 6 \mathrm{~cm}$ in size was resected and weighed $1.5 \mathrm{~kg}$. Macroscopically, there was grossly no normal renal tissue identified in the right kidney mass and measuring $15.5 \mathrm{~cm} \times 13.5 \mathrm{~cm} \times 8 \mathrm{~cm}$ in size, as reported by the pathologist. The tumor cut surfaces were variegated with yellowish, hemorrhagic, necrotic and cystic areas. The tumor was well encapsulated.

Microscopically, the nephrectomy specimen showed a renal cell tumor infiltrating as a complex papillary structures covered by moderately pleomorphic cells (Grade III). There are also areas of clear and granular cells. The tumor invades the renal capsule and perinephric fat. There are areas of necrosis, hemorrhage and cystic changes. Mitoses are brisk (Fig. 3). No tumor was seen in the renal vessel or renal pelvis. These features were consistent with papillary renal cell carcinoma.

Patient was seen 1 month postoperatively with incisional wound healed and repeated laboratory results normal as well as normal abdominal ultrasound scan. However, chest radiograph shows persistence of the canon ball lesions in both lung fields (Fig. 4).

She was duly referred to the radio-oncology unit for palliative systemic treatment and also to be followed up every 3 months at the urology clinic for surveillance checkup. However, she defaulted on the systemic therapy until she passed through the urology unit for a routine checkup five years post-cytoreduction surgery and still had no cough, hemoptysis nor weight loss. Contrastenhanced chest and abdominal CT scans were requested for her to assess the extent of chest metastasis and for any recurrence of the tumor. CBC, LFT, RFT and urinalysis done were all normal.

The contrast-enhanced chest and abdominal CT scans done showed multiple well-defined enhancing lesions in both lung fields of varying sizes, the largest at the right and left measuring $4.4 \mathrm{~cm} \times 4.1 \mathrm{~cm} \times 3.8 \mathrm{~cm}$ and $4.3 \mathrm{~cm} \times 4.3 \mathrm{~cm} \times 4.1 \mathrm{~cm}$, respectively, consistent with metastases (Fig. 5). Both lungs are well applied to the chest wall, and no pleural effusion is seen. The main bronchi appeared normal, and imaged vascular structures were normal. Bony thorax was normal, and there were no lytic nor sclerotic changes present.

The abdomen showed absent right kidney. The left kidney, liver, spleen and pancreas appear normal, and there is no evidence of ascites. This was consistent with pulmonary metastases from a previously resected right malignant kidney. 


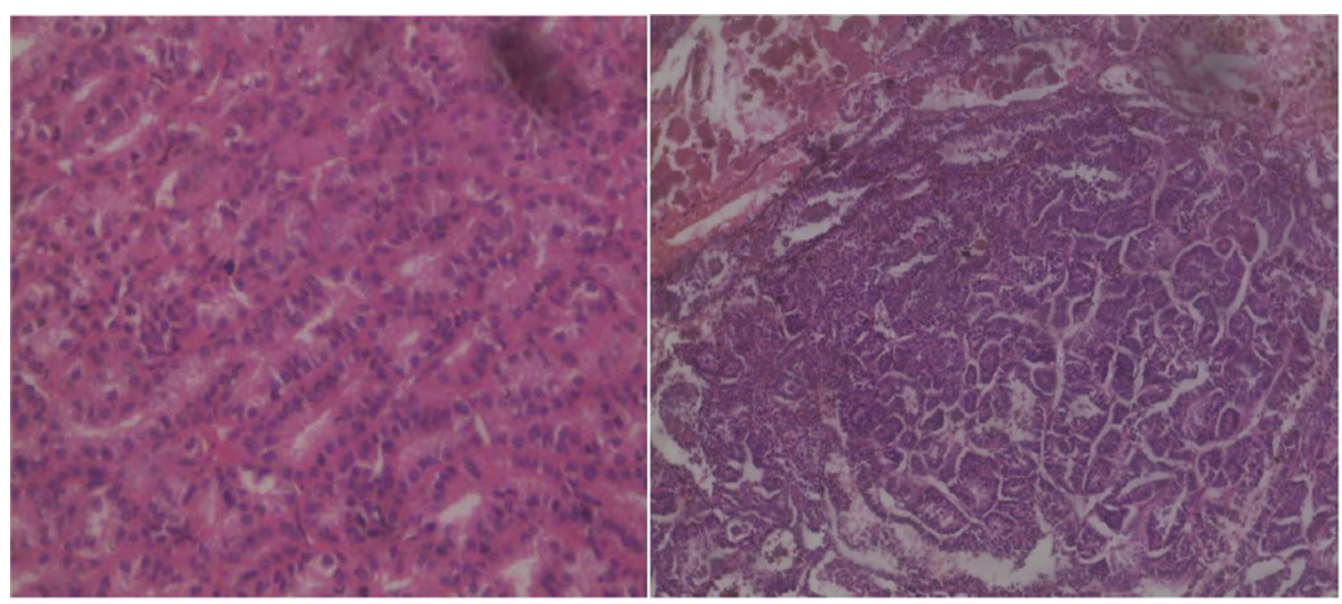

Fig. 3 H\&E stain slides showing papillae lined with pseudo-stratified layers of cells with abundant eosinophilic cytoplasm typical of papillary renal cell carcinoma (magnification $\times 100$ and $\times 40$, respectively)

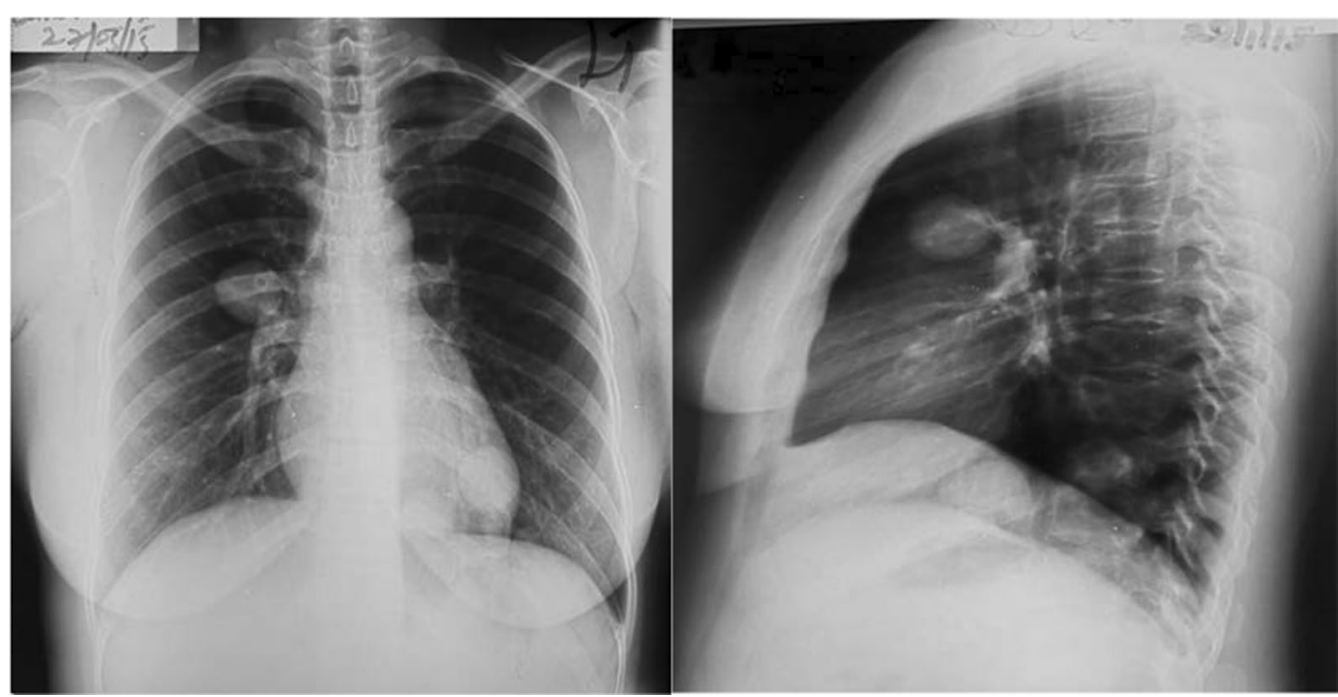

Fig. 4 Chest radiograph (posteroanterior (PA) and left lateral views) showing canon ball opacifications in both lung fields

From the contrast chest CT scan findings, the patient's bilateral lung metastases persisted but with minimal change in sizes and she could still benefit from palliative systemic therapy. Patient was still adamant on not having any palliative systemic treatment but, however, agreed to visit the urology clinic quarterly for active surveillance checkup.

\section{Discussion}

Papillary renal cell carcinoma (PRCC) is the second most common histologic subtype of RCC representing $10-15 \%$ of all RCCs [14] and shows slight male predominance [15]. The mean age of presentation ranges between 59 and 63 years [15], while in our case, patient was in her fourth decade of life. However, when RCC is diagnosed at younger age, the possibility of an underlying hereditary kidney cancer syndrome should be considered and this accounts for $3-5 \%$ of all RCCs [16-18]. The etiologic factors identified are mainly related to lifestyle such as smoking, obesity and hypertension [19-22]. However, a dose-related incidence is demonstrated for cigarette smoking and hypertension $[6,8]$. Also, having a first-degree relative with kidney cancer is also associated with an increased risk of RCC [23]. In our case, patient was young and had no family history of RCC or any other cancers and likely a sporadic type, though she 


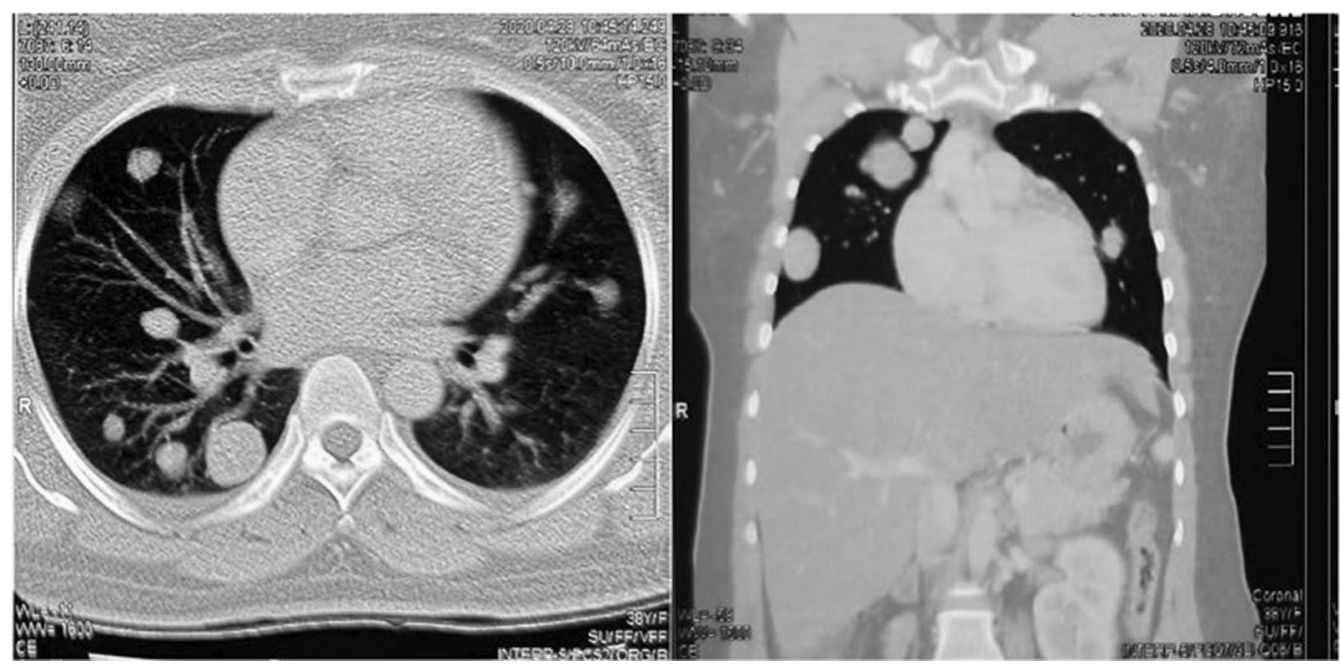

Fig. 5 Five-year postoperative contrast-enhancing CT images of the chest showing persisting multiple well-defined enhancing lesions in both lung fields

had no identifiable etiologic factor. More so, only $10 \%$ of RCC patients manifest the classical triad of hematuria, flank pain and a flank mass since RCC typically remains clinically occult for an extended period of time [24]. Unfortunately, patients presenting with this triad tend to typically have advanced disease. Approximately $40 \%$ of patients will present with hematuria or flank pain as isolated symptoms that on further workup reveal RCC [24], while in our situation, she presented with feeling of a flank mass and abdominal pain. PRCC is most often multifocal and bilateral and likely to metastasize to regional lymph nodes [14], while in our case the tumor was unilateral. They are also most often soft and friable, usually with abundant hemorrhage and necrosis consistent with the macroscopic findings in our case. In addition, PRCCs that appear cystic on radiographic studies tend to have solid-appearing tumor at the periphery, while most of the central tumor cells are suspended in hemorrhagic fluid [14].

PRCC is a malignant neoplasm originating from the renal tubular epithelium with mainly papillary or tubulopapillary architecture and often well circumscribed and encapsulated [15] as was also in our case macroscopically. It was subclassified based on the morphologic features into type 1 and type 2 tumors by Delahunt and Eble in 1997 [24]. Type 1 PRCCs have thin fibrovascular cores that are lined with a single layer of low cuboidal cells with scanty basophilic cytoplasm and low nuclear grade. Collections of foamy histiocytes and psammoma bodies (laminated calcifications) are more common in type 1 PRCCs [14]. Type 2 PRCCs have tall columnar pseudostratified cells with abundant eosinophilic cytoplasm and high-grade nuclei [14]. Generally, type 2 tumors (more aggressive) are associated with poorer prognosis than type 1 tumors (more indolent) [25]. Furthermore, several studies have established that type 2 PRCCs tumors metastasize and cause patient death more frequently than type 1 tumors [26-28]. Relating the clinical presentation and histology of our patient, it may be suggestive of type 2 PRCC than type 1 PRCC. Moreover, type 1 and type 2 PRCCs are not only clinically and pathologically different but also represent biologically different entities [29]. Although quite a number of similar mutations are found among the two morphologic subtypes of PRCC, each subtype is associated with characteristic mutations. There are two familial syndromes that are associated with increased risk of PRCC [30]. The first is the hereditary papillary RCC, an autosomal dominant syndrome characterized by multifocal, bilateral, type 1 PRCC and caused by mutation of the MET gene on chromosome 7q31 [30]. The MET gene encodes for a heterodimer transmembrane tyrosine-kinase receptor, with one known ligand (Hepatocyte Growth Factor) and a signaling via MAP-Kinase pathway, leading to increase in proliferative functions (invasion, aggressiveness, angiogenesis) [31]. Anomalies of MET pathway have been described in several other tumors including hepatocellular carcinomas (HCC), non-small cell lung cancer (NSCLC), breast cancer, ovarian cancer, colorectal cancer (CRC), head and neck squamous cell cancers (HNSCC), gastric carcinomas (GC) and cancers of unknown primary origin [31, 32]. The second is the Hereditary Leiomyomatosis RCC (HLRCC) syndrome that tends to have an early age of onset and associated with type 2 PRCC, cutaneous and 
uterine leiomyomas. This is however, caused by an inactivating mutation of the fumarate hydratase $(\mathrm{FH})$ gene which encodes the enzyme that converts fumarate to malate in the Krebs cycle [30].

RCC potentially metastasizes to many different organs and has a variable natural history. Some may be rapidly progressive, while others will be indolent requiring no immediate systemic therapy [3]. Moreover, about twothirds of the metastatic renal cell carcinoma (mRCC) cases present with more than one metastatic site $[4,9]$. Consequently, our patient had multiple lung metastases which corresponds to pattern of spread to other organs by this tumor. Significantly, several clinical factors have been associated with improved response to treatment for metastatic RCC. Some of these clinical factors necessary for determining the suitability of a patient for surgical intervention include performance status, length of disease-free interval, synchronous or metachronous metastasis, burden of metastatic disease and number of locations and sites involved [33]. Though there have been many advances in the treatment for metastatic RCC, including the development and approval of immunotherapy regimens, complete responses are still rare. As such, surgical management of metastatic disease remains an important aspect of therapy for long-term disease control. Studies have revealed a survival benefit in patients who receive cytoreductive nephrectomy prior to systemic immunotherapy (median survival 13.6 months versus 7.8 months) and with the greatest benefit of cytoreductive nephrectomy in patients with good performance status [34-36]. In addition, a small percentage of patients will experience spontaneous metastatic tumor regression following cytoreductive nephrectomy [37, 38]. Therefore, with the exception of patients with poor performance status, high volume extrarenal disease and critical brain lesions, cytoreductive nephrectomy should be the first palliative treatment for patients with metastatic RCC who can tolerate surgery and this was exactly the form of treatment we initially offered to our patient. However, without any palliative systemic treatment, patient has had a progression-free survival period of 5 years now with no metachronous metastases nor recurrence of the tumor.

Subsequently, our patient could have also been offered incomplete or complete metastasectomy with the aim of improving the long-term survival. Patients with isolated pulmonary metastases are known to have a favorable prognosis compared with other organ sites [39], and the largest cumulative reported experience with RCC metastasectomy exists for patients with lung involvement. However, in all the various studies, the reported 5-year overall survival (OS) rates of patients who underwent metastasectomy for pulmonary metastasis were around $50 \%$, ranging from 45 to $60 \%$, and in addition, studies also support complete metastasectomy as being superior for patient outcomes compared to incomplete metastasectomy since the 5-year OS was significantly decreased to less than $10 \%$ for patients treated with incomplete metastasectomy [40-42], which further emphasizes the importance of achieving complete resection of pulmonary metastatic lesions for maximum survival benefit. The pulmonary function of the patient is, however, essential, as in any pulmonary resection, and is associated with tolerance to surgery, recovery and prognosis [43]. In well-selected patients, pulmonary metastasectomy is reasonably well tolerated with an approximately $10 \%$ incidence of moderate severity complications (i.e., venous thrombosis, myocardial infarction, cardiac arrhythmia, transient cerebral ischemia, prolonged air leak and pneumonia) [5]. Perioperative mortality among these patients was about 1.1\% [43-48]. Furthermore, patients with small solitary or oligometastases, no lymph node involvement and long disease-free interval seemed to have the best outcomes, especially if complete resection can be achieved [43-48]. In our case, she had multiple metastases in both lung fields and, though not oligometastases, could still have benefitted from metastasectomy since parenchyma-saving techniques, such as laser resection, could even enable removal of pulmonary metastases and provide comparable long-term survival when complete resection is achieved [42].

In addition to the poor prognosis of mRCC, there is very high intrathoracic recurrence rate even after complete surgical resection of the lung metastases of about $50-60 \%$ and again, reoperation is still feasible in these patients but is limited by the remaining pulmonary reserve, often resulting in functionally inoperable patients $[49,50]$. The use of systemic medical treatment for patients with $\mathrm{mRCC}$ has gained prominence over the years but, however, there seems to be a lack of effective systemic therapy for patients with metastases. RCC is highly resistant to chemotherapy and hormonal therapy because no agent consistently achieves a response in more than $10 \%$ of patients [51]. Until recently, treatment options of mRCC were limited to cytokine therapy with interferon alpha (IFN- $\alpha$ ) and/or high-dose interleukin 2 (IL-2) achieving responses in $10 \%$ to $20 \%$ of patients [9]. Sunitinib, pazopanib and sorafenib are multityrosine kinase inhibitors (TKI) that between them affect vascular endothelial growth factor (VEGF), c-kit, plateletderived growth factor-beta (PDGFR- $\beta$ ), fms-like tyrosine kinase 3 (FLT3) and BRAF [52, 53]. These drugs have been approved for metastatic RCC as first-line or second-line options [54-56]. Sunitinib, for instance, stabilizes disease in $48 \%$ of patients and reduces tumor size in 30\% [12]. However, the mammalian Target of Rapamycin (mTOR) inhibitors, temsirolimus and everolimus, 
are recommended for poor-prognosis patients as first line and for second line after TKI failure, respectively. The mTOR regulates many downstream signally paths, including the HIF-1, and controls metabolism, cell growth and angiogenesis [57, 58]. Unfortunately, complete responses with these medications are rare $[11,12]$. Again, as many patients will achieve a partial response to molecular targeted agents, neoadjuvant medical treatment has been suggested prior to difficult-to-resect primary tumors and associated metastases [59]. In addition, a recent study of the use of sorafenib (median duration of 33 days) prior to nephrectomy revealed a median $10 \%$ tumor size reduction in most patients with only $17 \%$ experiencing tumor growth [60]. Also, response to neoadjuvant sunitinib has also been reported though the response was much lower compared to sorafenib. A study of patients with disease deemed surgically unresectable; only about $21 \%$ had responses that allowed for surgical extirpation [61]. Moreover, early experiences suggest neoadjuvant sorafenib and sunitinib are well tolerated, as few significant postoperative complications have been reported $[60,61]$. Therefore, when selecting neoadjuvant medical therapy, it is imperative to consider that the benefits of these medications are not established for brain metastases or nonclear cell RCC histologic subtypes [5]. In addition, the majority of tumor downsizing occurs in the first cycle of treatment and those who do not respond initially are unlikely to respond with future cycles [62]. Neoadjuvant therapy was, however, not indicated in this case presented.

RCC is not a radio-resistant tumor, and many patients can achieve palliation of symptoms related to their cancer through radiation therapy (RT) [63]. The new radiation techniques, such as stereotactic body RT (SBRT), may improve outcomes compared to traditional external beam RT. SBRT is another treatment option for oligometastatic RCC. Unlike the conventional radiotherapy, SBRT involves delivery of very conformal, ultra-hypofractionated radiation over 1-5 fractions, where the goal is to eradicate or provide long-term local control of the treated tumor(s) [63]. In patients with inoperable, earlystage RCC, SBRT to the primary tumor results in very high local control rates $[64,65]$ Similarly, high local control rates of about $90 \%$ are observed when using SBRT to treat RCC metastases in various body sites (thoracic, abdominal, soft tissue, bone, brain) [64, 65]. Furthermore, SBRT can be an alternative to surgical metastasectomy in patients who are inoperable or whose tumor(s) are not easily resectable without morbidity and can also be complimentary to surgical resection when there are multiple metastases where a combined approach can be considered to spare patients multiple surgical procedures [63]. However, there is no role for radiation "adjuvant" therapy in a no evidence of disease (NED) situation after complete resection of metastases [66]. In addition, thermal ablation may be a preferred option for metastases in locations that are sometimes difficult to safely resect (i.e., liver) [5]. However, in oligometastatic RCC, the other local treatments that can be considered are cryotherapy and radiofrequency ablation (RFA) with the goal of delaying the need to start or change systemic therapy [63]. The patient in this case chose not to report for any form of adjuvant therapy.

The absence of comorbidities such as chronic kidney disease, hypertension, diabetes and patients' good performance status may have contributed to the improved prognosis [67]. Our patient with her good performance status was offered the opportunity to benefit from systemic palliative therapy after undergoing cytoreductive nephrectomy for her mRCC but did not honor her appointment. Moreover, she has had a good 5-year survival without any palliative therapy. She, however, currently favors an active surveillance of her condition since it is well known from a retrospective study that the delayed start of targeted therapy failed to independently predict worse overall survival in mRCC patient [68]. Thus, active surveillance is an option in a well-selected group of patients with indolent, asymptomatic and good-risk mRCC [68]. This study is limited by the lack of tissue diagnosis of the lung lesions to confirm pulmonary metastases as other lung lesions like fibromas, lipomas, hamartomas, fungus or septic emboli may coexist with the PRCC and could be misdiagnosed as pulmonary metastases. Despite the lack of family history, genetic studies to confirm a diagnosis of hereditary papillary renal cell carcinoma (HPRCC) nor hereditary leiomyomatosis and renal cell carcinoma (HLRCC) could have been done due to the young age of patient and good prognosis of the disease.

\section{Conclusion}

Our patient with metastatic RCC, without undergoing metastasectomy nor palliative systemic therapy, remained stable with 5-year progression-free survival post-cytoreductive nephrectomy.

\section{Abbreviations \\ RCC: renal cell carcinoma; mRCC: metastatic renal cell carcinoma; PRCC: papil- lary renal cell carcinoma; CT: computerized tomography; ECG: electrocardio- gram; CBC: complete blood count; LFT: liver function test,; RFT: renal function test; ECOG: eastern Cooperative Oncology Group; OS: overall survival; TKI: tyrosine kinase inhibitors; SBRT: stereotactic body radiation therapy.}

\section{Acknowledgements}

None.

\section{Authors' contributions}

EOO was involved in the conception of the study and drafting the manuscript and revising it critically for important intellectual content. BABA helped in drafting the manuscript and revising it critically for important intellectual 
content. PKA helped read the histology, provided details of the slides and contributed to revising it for intellectual content. HA helped put the case report together and helped draft the manuscript. AA-A helped put the case report together and helped draft the manuscript. GAR helped draft the manuscript and contributed to revising it for intellectual content. POMM helped draft the manuscript and contributed to revising it for intellectual content. PWO helped with the literature search and drafting of the manuscript. EAA helped with the literature search and drafting of the manuscript. EGI helped with the literature search and drafting of the manuscript. All authors read and approved the final manuscript.

\section{Funding}

No funding was received for this study.

\section{Availability of data and materials}

All data generated during this study are included in this published article.

\section{Ethics approval and consent to participate}

Written informed consent was obtained from the patients for publication of this case and the accompanying images. Permission was also granted by the Health Monitoring and Evaluation and Research Department of the Cape Coast Teaching Hospital for this study.

\section{Consent for publication}

The patient provided written informed consent for publication of this case and the accompanying images.

\section{Competing interests}

The authors declare that they have no competing interests.

\section{Author details}

${ }^{1}$ Department of Surgery, Cape Coast Teaching Hospital, Cape Coast, Ghana. ${ }^{2}$ Department of Surgery, School of Medical Sciences, College of Health Sciences, University of Cape Coast, Cape Coast, Ghana. ${ }^{3}$ Department of Pathology, School of Medical Sciences, College of Health Sciences, University of Cape Coast, Cape Coast, Ghana. ${ }^{4}$ Cape Coast Teaching Hospital, Cape Coast, Ghana.

Received: 19 June 2020 Accepted: 14 December 2020

Published online: 07 January 2021

\section{References}

1. Chow WH, Dong LM, Devesa SS (2010) Epidemiology and risk factors for kidney cancer. Nat Rev Urol. 7(5):245-257. https://doi.org/10.1038/nruro I.2010.46

2. Hsieh JJ, Purdue MP, Signoretti S, Swanton C, Albiges L, Schmidinger M et al (2017) Renal cell carcinoma. Nat Rev Dis Primers 3:17009. https://doi. org/10.1038/nrdp.2017.9

3. Rini BI, Dorff TB, Elson P, Rodriguez CS, Shepard D, Wood L et al (2016) Active surveillance in metastatic renal-cell carcinoma: a prospective, phase 2 trial. Lancet Oncol 17(9):1317-1324

4. Bianchi M, Sun M, Jeldres C, Shariat SF, Trinh QD, Briganti A et al (2012) Distribution of metastatic sites in renal cell carcinoma: a populationbased analysis. Ann Oncol 23(4):973-980. https://doi.org/10.1093/annon c/mdr362

5. Breau RH, Blute ML (2010) Surgery for renal cell carcinoma metastases. Curr Opin Urol 20:375-378. https://doi.org/10.1097/MOU.0b013e3283 3c7ada

6. Campbell SC, Novick AC, Belldegrun A, Blute ML, Chow GK, Derweesh IH et al (2009) Guideline for management of the clinical T1 renal mass. J Urol 182(4):1271-1279. https://doi.org/10.1016/j.juro.2009.07.004

7. Ljungberg B, Cowan NC, Hanbury DC, Hora M, Kuczyk MA, Merseburger AS et al (2010) EAU guidelines on renal cell carcinoma: the 2010 update. Eur Urol 58(3):398-406. https://doi.org/10.1016/j.eururo.2010.06.032

8. National Comprehensive Cancer Network. (2014) Kidney cancer. NCCN Clinical Practice Guideline in Oncology (NCCN GuidelinesTM) Version 1

9. Motzer RJ, Bander NH, Nanus DM (1996) Renal-cell carcinoma. N Engl J Med 335:865-875. https://doi.org/10.1056/NEJM199609193351207

10. Motzer RJ, Mazumdar M, Bacik J, Berg W, Amsterdam A, Ferrara J (1999) Survival and prognostic stratification of 670 patients with advanced renal cell carcinoma. J Clin Oncol 17:2530-2540. https://doi.org/10.1200/ JCO.1999.17.8.2530

11. Escudier B, Eisen T, Stadler WM, Szczylik C, Oudard S, Staehler M et al (2009) Sorafenib for treatment of renal cell carcinoma: final efficacy and safety results of the phase III treatment approaches in renal cancer global evaluation trial. J Clin Oncol 27:3312-3318. https://doi.org/10.1200/ JCO.2008.19.5511

12. Motzer RJ, Hutson TE, Tomczak P, Dror Michaelson M, Bukowski RM, Oudard S et al (2009) Overall survival and updated results for sunitinib compared with interferon alfa in patients with metastatic renal cell carcinoma. J Clin Oncol 27:3584-3590. https://doi.org/10.1200/JCO.2008.20.1293

13. Den Hengst WA, Hendriks JMH, Van Schil PEY (2011) Lung metastatic disease: surgical resection and locoregional chemotherapy. JThorac Oncol 6:1373-1378. https://doi.org/10.5152/tcb.2012.29

14. Tannir NM (2014) Renal cell carcinoma. Oxford University Press, New York, pp 10-11

15. Delahunt B, Algaba F, Eble J, Cheville J, Amin MB, Algani P et al. (2016) Papillary renal cell carcinoma. World Health organisation classication of tumours. Pathology and genetics of tumours of the urinary system and male genital system. 4th Edn, Lyon, IARC Press, pg 21-23

16. Moch H, Cubilla AL, Humphrey PA, Reuter VE, Ulbright TM (2016) The 2016 WHO classification of tumours of the urinary system and male genital organs -part A: renal, penile, and testicular tumours. Eur Urol 70(1):93-105. https://doi.org/10.1016/j.eururo.2016.02.029

17. Haas NB, Nathanson KL (2014) Hereditary kidney cancer syndromes. Adv Chronic Kidney Dis 21(1):81-90. https://doi.org/10.1053/j. ackd.2013.10.001

18. Adeniran AJ, Shuch B, Humphrey PA (2015) Hereditary renal cell carcinoma syndromes: clinical, pathologic, and genetic features. Am J Surg Pathol 39(12):e1-e18. https://doi.org/10.1097/PAS.00000000000000562

19. Hunt JD, van der Hel OL, McMillan GP, Boffetta P, Brennan P (2005) Renal cell carcinoma in relation to cigarette smoking: meta-analysis of 24 studies. Int J Cancer 114(1):101-108. https://doi.org/10.1002/ijc.20618

20. Pischon T, Lahmann PH, Boeing H, Tjønneland A, Halkjaer J, Overvad K et al (2006) Body size and risk of renal cell carcinoma in the European Prospective Investigation into Cancer and Nutrition (EPIC). Int J Cancer 118(3):728-738. https://doi.org/10.1002/ijc.21398

21. Weikert S, Boeing H, Pischon T, Weikert C, Olsen A, Tjonneland A et al (2008) Blood pressure and risk of renal cell carcinoma in the European prospective investigation into cancer and nutrition. Am J Epidemiol 167(4):438-446. https://doi.org/10.1093/aje/kwm321

22. Clague J, Lin J, Cassidy A, Matin S, Tannir NM, Tamboli P et al (2009) Family history and risk of renal cell carcinoma: results from a case-control study and systematic meta-analysis. Cancer Epidemiol Biomarkers Prev 18(3):801-807. https://doi.org/10.1158/1055-9965.EPI-08-0601

23. Lane BR, Canter DJ, Rini BI, Uzzo RG (2015) Cancer of the kidney. In: Devit VT, Lawrence TS, Rosenberg SA (eds) DeVita, Hellman, and Rosenberg's principles and practice of oncology, 10th edn. Wolters Kluwer Health, Philadelphia, pp 865-884

24. Delahunt B, Eble JN (1997) Papillary renal cell carcinoma: a clinicopathologic and immunohistochemical study of 105 tumors. Mod Pathol Off J U S Can Acad Pathol Inc 10:537-544

25. Mejean A, Hopirtean V, Bazin JP, Larousserie F, Benoit H, Chretien Y et al (2003) Prognostic factors for the survival of patients with papillary renal cell carcinoma: meaning of histological typing and multifocality. J Urol 170:764-767. https://doi.org/10.1097/01.ju.0000081122.57148.ec

26. Delahunt B, Eble JN, McCredie MR, Bethwaite PB, Stewart JH, Bilous AM (2001) Morphologic typing of papillary renal cell carcinoma: comparison of growth kinetics and patient survival in 66 cases. Hum Pathol 32:590-595. https://doi.org/10.1053/hupa.2001.24984

27. Pignot G, Elie C, Conquy S, Vieillefond A, Flam T, Zerbib M et al (2007) Survival analysis of 130 patients with papillary renal cell carcinoma: prognostic utility of type 1 and type 2 subclassification. Urology 69:230-235. https://doi.org/10.1016/j.urology.2006.09.052

28. Allory Y, Ouazana D, Boucher E, Thiounn N, Vieillefond A (2003) Papillary renal cell carcinoma. Prognostic value of morphological subtypes in a clinicopathologic study of 43 cases. Virtuous Arch Int J Pathol 442:336442. https://doi.org/10.1007/s00428-003-0787-1

29. Linehan WM, Spellman PT, Ricketts CJ, Creighton CJ, Fei SS, Davis C et al (2016) Comprehensive molecular characterization of papillary renal-cell 
carcinoma the cancer genome atlas research network. N Engl J Med 374(2):135-145. https://doi.org/10.1056/NEJMoa1505917

30. Petejova N, Martinek A (2016) Renal cell carcinoma: review of etiology, pathophysiology and risk factors. Biomed Pap Med Fac Univ Palacky Olomouc Czech Repub 160(2):183-194. https://doi.org/10.5507/bp.2015.050

31. Appleman $L J$ (2011) MET signaling pathway: a rational target for cancer therapy. J Clin Oncol 29:4837-4838. https://doi.org/10.1200/ JCO.2011.37.7929

32. Petrini I (2015) Biology of MET: a double life between normal tissue repair and tumor progression. Ann Transl Med. 3:82. https://doi.org/10.3978/j. issn.2305-5839.2015.03.58

33. Leibovich BC, Cheville JC, Lohse CM, Zincke H, Frank I, Kwon ED et al (2005) A scoring algorithm to predict survival for patients with metastatic clear cell renal cell carcinoma: a stratification tool for prospective clinical trials. J Urol. 174(5):1759-1763. https://doi.org/10.1097/01.ju.0000177487 .64651.3a discussion 63

34. Flanigan RC, Mickisch G, Sylvester R, Tangen C, Van Poppel H, Crawford ED (2004) Cytoreductive nephrectomy in patients with metastatic renal cancer: a combined analysis. J Urol 171:1071-1076. https://doi. org/10.1097/01.ju.0000110610.61545.ae

35. Flanigan RC, Salmon SE, Blumenstein BA, Bearman SI, Roy V, McGrath PC et al (2001) Nephrectomy followed by interferon alfa-2b compared with interferon alfa-2b alone for metastatic renal-cell cancer. N Engl J Med 345:1655-1659. https://doi.org/10.1056/NEJMoa003013

36. Mickisch GH, Garin A, Van Poppel H, De Prijck L, Sylvester R et al (2001) Radical nephrectomy plus interferon-alfa-based immunotherapy compared with interferon alfa alone in metastatic renal-cell carcinoma: a randomised trial. Lancet 358:966-970. https://doi.org/10.1016/s0140 -6736(01)06103-7

37. Marcus SG, Choyke PL, Reiter R, Jaffe GS, Alexander RB, Linehan WM et al (1993) Regression of metastatic renal cell carcinoma after cytoreductive nephrectomy. J Urol 150(2 Pt 1):463-466. https://doi.org/10.1016/s0022 $-5347(17) 35514-3$

38. Gleave ME, Elhilali M, Fradet Y, Davis I, Venner P, Saad F et al (1998) Interferon gamma-1b compared with placebo in metastatic renal-cell carcinoma. Canadian Urologic Oncology Group. N Engl J Med 338:1265-1271. https://doi.org/10.1056/nejm199804303381804

39. Ouzaid I, Capitanio U, Staehler M, Wood CG, Leibovich BC, Ljungberg B et al (2019) Surgical metastasectomy in renal cell carcinoma: a systematic review. Eur Urol Oncol 2(2):141-149. https://doi.org/10.1016/j. euo.2018.08.028

40. Zhao Y, Li J, Li C, Fan J, Lui L (2017) Prognostic factors for overall survival after lung metastasectomy in renal cell cancer patients: a systematic review and meta-analysis. Int J Surg 41:70-77. https://doi.org/10.1016/j. ijsu.2017.03.062

41. Ohtaki Y, Shimizu K, Aokage K, Nakao M, Yoshida J, Kamiyoshihara M et al (2017) Histology is a prognostic indicator after pulmonary metastasectomy from renal cell carcinoma. World J Surg 41(3):771-779. https://doi. org/10.1007/s00268-016-3802-9

42. Baier B, Kern A, Kaderali L, Bis B, Koschel D, Rolle A (2015) Retrospective survival analysis of 237 consecutive patients with multiple pulmonary metastases from advanced renal cell carcinoma exclusively resected by a 1318-nm laser. Interact CardioVasc Thorac Surg 21:211-217. https://doi. org/10.1093/icvts/ivv120

43. Murthy SC, Kim K, Rice TW, Rajeswaran J, Bukowski R, DeCamp MM et al (2005) Can we predict long-term survival after pulmonary metastasectomy for renal cell carcinoma? Ann Thorac Surg 79:996-1003. https://doi. org/10.1016/j.athoracsur.2004.08.034

44. Piltz S, Meimarakis G, Wichmann MW, Hatz R, Schildberg FW, Fuerst $H$ (2002) Long-term results after pulmonary resection of renal cell carcinoma metastases. Ann Thorac Surg 73:1082-1087. https://doi. org/10.1016/s0003-4975(01)03602-5

45. Friedel G, Hurtgen M, Penzenstadler M, Kyriss T, Toomes H (1999) Resection of pulmonary metastases from renal cell carcinoma. Anticancer Res 19(2C):1593-1596

46. Pfannschmidt J, Hoffmann H, Muley T, Krysa S, Trainer C, Dienemann H (2002) Prognostic factors for survival after pulmonary resection of metastatic renal cell carcinoma. Ann Thorac Surg 74:1653-1657

47. Cerfolio RJ, Allen MS, Deschamps C, Daly RC, Wallrichs SL, Trastek VF et al (1994) Pulmonary resection of metastatic renal cell carcinoma. Ann Thorac Surg 57:339-344
48. Hofmann HS, Neef H, Krohe K, Andreev P, Silber R-E (2005) Prognostic factors and survival after pulmonary resection of metastatic renal cell carcinoma. Eur Urol 48:77-81. https://doi.org/10.1016/j.eururo.2005.03.004 discussion 81-2

49. Downey RJ (1999) Surgical treatment of pulmonary metastases. Surg Oncol Clin N Am 8:341

50. Van Schil PE (2002) Surgical treatment for pulmonary metastases. Acta Clin Belg 57:333-339

51. Motzer RJ, Vogelzang NJ (1997) Chemotherapy for renal cell carcinoma. In: Raghaven D, Scher HI, Leibel SA et al (eds) Principles and practice of genitourinary oncology. Lippincott- Raven, Philadelphia, pp 885-896

52. Oxelmark E, Hornberg JJ (2007) Finding the way in the jungle of kinase drug targets. Drug Discov Today Technol 4(3-4):e91-e95

53. Wilhelm S, Carter C, Lynch M, Lowinger T, Dumas J, Smith RA et al (2006) Discovery and development of sorafenib: a multikinase inhibitor for treating cancer. Nat Rev Drug Discovery 5(10):835-844. https://doi. org/10.1038/nrd2130

54. Motzer RJ, Hutson TE, Tomczak P, Dror Michaelson M, Bukowski RM, Rixe $O$ et al (2007) Sunitinib versus interferon alfa in metastatic renal-cell carcinoma. N Engl J Med 356:115-124. https://doi.org/10.1056/NEJMo a065044

55. Figlin R, Hutson TE, Tomczak P, Michaelson MD, Bukowski RM, Négrier $S$ et al (2008) Overall survival with sunitinib versus interferon (IFN)-alfa as first-line treatment of metastatic renal cell carcinoma (mRCC). J Clin Oncol. 26:5024

56. Szczylik T, Demkow M, Staehler F, Rolland F, Negrier S, Hutson TE et al (2007) Randomized phase II trial of first-line treatment with sorafenib versus interferon in patients with advanced renal cell carcinoma: final results. J Clin Oncol 25(18):5025

57. Hudes G, Carducci M, Tomczak P, Dutcher J, Figlin R, Kapoor A et al (2007) Temsirolimus, interferon alfa, or both for advanced renal-cell carcinoma. N Engl J Med 356:2271-2281. https://doi.org/10.1056/NEJMoa066838

58. Motzer R, Escudier B, Oudard S, Hutson TE, Porta C, Bracarda S et al (2008) Efficacy of everolimus in advanced renal cell carcinoma: a double-blind, randomized, placebo-controlled phase III trial. The Lancet 372:449-456. https://doi.org/10.1016/S0140-6736(08)61039-9

59. Shuch B, Riggs SB, LaRochelle JC, Kabbinavar FF, Avakian R, Pantuck AJ et al (2008) Neoadjuvant targeted therapy and advanced kidney cancer: observations and implications for a new treatment paradigm. BJU Int 102:692-696. https://doi.org/10.1111/j.1464-410X.2008.07660.x

60. Cowey CL, Amin C, Pruthi RS, Wallen EM, Nielsen ME, Grigson G et al (2010) Neoadjuvant clinical trial with sorafenib for patients with stage II or higher renal cell carcinoma. J Clin Oncol 28:1502-1507. https://doi. org/10.1200/JCO.2009.24.7759

61. Thomas AA, Rini BI, Lane BR, Garcia J, Dreicer R, Klein EA et al (2009) Response of the primary tumor to neoadjuvant sunitinib in patients with advanced renal cell carcinoma. J Urol 181:518-523. https://doi. org/10.1016/j.juro.2008.10.001 discussion $\mathbf{5 2 3}$

62. van der Veldt AAM, Meijerink MR, van den Eertwegh AJM, Bex A, de Gast G, Haanen JBAG et al (2008) Sunitinib for treatment of advanced renal cell cancer: primary tumor response. Clin Cancer Res 14:2431-2436. https:// doi.org/10.1158/1078-0432.CCR-07-4089

63. Hotte SJ, Kapoor A, Basappa NS, Bjarnason G, Canil C, Conter HJ et al (2019) Management of advanced kidney cancer: kidney cancer research network of Canada (KCRNC) consensus update 2019. Can Urol Assoc J 13(10):343-354. https://doi.org/10.5489/cuaj.6256

64. Siva S, Pham D, Gill S, Corcoran NM, Foroudi F (2012) A systematic review of stereotactic radiotherapy ablation for primary renal cell carcinoma. BJU Int 110:E737-E743. https://doi.org/10.1111/j.1464-410X.2012.11550.x

65. Siva S, Pham D, Kron T, Bressel M, Lam J, Tan TH et al (2017) Stereotactic ablative body radiotherapy for inoperable primary kidney cancer: a prospective clinical trial. BJU Int 120:623-630. https://doi.org/10.1111/ bju. 13811

66. Motzer RJ, Haas NB, Donskov F, Gross-Goupil M, Varlamov S, Kopyltsov E et al (2017) Randomized phase III trial of adjuvant pazopanib versus placebo after nephrectomy in patients with localized or locally advanced renal cell carcinoma. J Clin Oncol 35(35):3916-3923. https://doi. org/10.1200/JCO.2017.73.5324

67. Schips L, Lipsky K, Zigeuner R, Salfellner M, Winkler S, Langner C et al (2003) Impact of tumor-associated symptoms on the prognosis of patients with renal cell carcinoma: a single-center experience of 683 
patients. Urology. 62(6):1024-1028. https://doi.org/10.1016/s0090 $-4295(03) 00763-5$

68. Woldu SL, Matulay JT, Clinton TN et al (2018) Incidence and outcomes of delayed targeted therapy after cytoreductive nephrectomy for metastatic renal-cell carcinoma: a nationwide cancer registry study. Clin Genitourin Cancer 16:e1221-e1235. https://doi.org/10.1016/j.clgc.2018.08.001

\section{Publisher's Note}

Springer Nature remains neutral with regard to jurisdictional claims in published maps and institutional affiliations.
Submit your manuscript to a SpringerOpen ${ }^{\circ}$ journal and benefit from:

- Convenient online submission

- Rigorous peer review

- Open access: articles freely available online

- High visibility within the field

- Retaining the copyright to your article

Submit your next manuscript at $\boldsymbol{\triangleright}$ springeropen.com 